\title{
A contravenção do patriarcado na ficção de Cíntia Moscovich
}

Cíntia Moscovich (1958), autora gaúcha de dois romances para adultos, um romance infanto-juvenil e quatro coletâneas de contos, descreve-se como "profundamente judia e profundamente brasileira" (Dias, 2012, p. 82). ${ }^{2} \mathrm{Na}$ ficção de outros escritores judeus proeminentes do Rio Grande do Sul, esses mesmos traços de identidade, ou seja, as filiações nacional, religiosa e/ou étnica, ora resistem um ao outro, ora se excluem mutuamente. No romance O centauro no jardim (1980), Moacyr Scliar (1937-2011) explora a dualidade identitária e os obstáculos à assimilação através da caracterização de Guedali, um protagonista metade homem, metade cavalo; as vinhetas de Filipson (1967), de Frida Alexandr (1906-1972), registram conflitos entre o núcleo judaico do título e a vizinhança gói; e a trilogia familiar de Adão Voloch, compreendida entre O colono judeu-açu (1985), Um gaúcho a pé (1987) e Os horizontes do sol (1987), documenta o repetido fracasso dos protagonistas judeus, Natálio Litvinoff e seu filho, Arturo, para se estabelecerem como brasileiros.

Ao contrário dos conterrâneos, Moscovich não justapõe a brasilidade e o judaísmo como características antagônicas; de fato, suas personagens raramente se defrontam com o antissemitismo, sendo o conto "O telhado e o violinista", de Arquitetura do arco-íris (2004), uma exceção notável. A ficção da autora, porém, problematiza tanto a cultura nacional quanto a tradição judaica, apresentando-as como sustentáculos de padrões patriarcais contrários ao progresso e ao igualitarismo.

Várias das protagonistas de Moscovich, em sua maioria femininas, transgridem as normas do patriarcado, o qual tem três correlativos principais em sua obra: a ditadura militar no Brasil (1964-1985), a Halachá (a lei judaica) e a autoridade paterna. As transgressões também assumem diferentes formas, incluindo relações amorosas vedadas (entre

\footnotetext{
${ }^{1}$ Doutor em estudos literários e professor de espanhol e português da California State University, Fullerton, CA, Estados Unidos. E-mail: jhussar@fullerton.edu

${ }^{2}$ Este estudo deve-se, em grande parte, à minha participação no seminário de verão "Brazilian literature: twentieth-century urban fiction", dirigido por David W. Foster e patrocinado pelo Fundo Nacional para as Humanidades (NEH), em junho-julho de 2013.
} 
pessoas do mesmo sexo ou entre judeus e góis) e inconformismo com decisões relacionadas à carreira. Os contos e romances de Moscovich tendem a salientar a dinâmica pai-filha como um meio para questionar padrões patriarcais, representando, assim, conflitos políticos, sociais e religiosos mediante duas figuras arquetípicas: o pai conservador e a filha rebelde (porém respeitosa). O presente artigo analisa as interações pai-filha em relação aos esforços da autora para reconciliar a brasilidade e o judaísmo com ideias progressistas sobre sexualidade e gênero. Embora enfatize os romances para adultos Duas iguais (1998) e Por que sou gorda, mamãe? (2006), este estudo considera a ficção de Moscovich como um todo, visando, desse modo, propiciar uma perspectiva abrangente da temática.

A análise literária que se segue parte dos principais pontos da teoria queer, a qual fornece a estrutura acadêmica e a nomenclatura necessárias para compreender e descrever as caracterizações e situações das personagens de Moscovich. Os estudos queer rejeitam binarismos essencialistas como "heterossexual/homossexual" e "homem/mulher" em favor de um entendimento da identidade como algo multifacetado e fluído, minando dessa maneira as estruturas do patriarcado heteronormativo e heterossexista (Foster, 2009, p. 15). Além disso, estabelecem uma distinção nítida entre sexo, identidade de gênero, expressão de gênero e orientação sexual, ${ }^{3}$ aspectos identitários cuja combinação varia de uma pessoa para outra.

Essa capacidade de diferenciação torna-se crucial para estudar as personagens femininas de Moscovich, as quais resistem a uma categorização fácil conforme sistemas tradicionais e ultrapassados, seja pela complexidade das caracterizações, seja pela ambiguidade das narrativas.

Antes de prosseguir com a análise da ficção, será necessário considerar como o Estado brasileiro e as diferentes denominações judaicas têm respondido às "transgressões" anteriormente mencionadas durante os períodos representados por Moscovich, a fim de contextualizar as tensões e os conflitos experimentados pelas personagens.

\footnotetext{
${ }^{3}$ De acordo com a Associação Americana de Psicologia (APA), "sexo" refere-se ao status biológico da pessoa; "identidade de gênero", ao sentido de si mesmo como masculino, feminino ou transgênero; "expressão de gênero", à maneira em que a pessoa comunica o gênero; e "orientação sexual", ao(s) sexo(s) pelo(s) qual(is) a pessoa sente atração física e/ou emocional (APA, 2011, s.p.).
} 


\section{Fatores políticos, religiosos e culturais na obra de Moscovich}

A primeira transgressão a ser considerada, o ato homoerótico, ${ }^{4}$ contravém os valores da cultura patriarcal brasileira, segundo a qual a homossexualidade tem representado, em distintos momentos históricos, uma doença, um pecado, um perigo social e um atentado contra a família (Green, Céspedes e Quinalha, 2014, p. 300). A homofobia tornase particularmente intensa no Brasil durante a ditadura militar, período marcado pela perseguição e a opressão das minorias sexuais. Segundo Foster, a concepção de homossexualidade tem origem em programas patriarcais, cuja visão de controle social total parte do controle do corpo individual (Foster, 1991, p. 4); portanto, durante a ditadura militar, o Estado julgava necessária a violência contra pessoas LGBT para garantir a moral e a segurança nacionais (Green, Céspedes e Quinalha, 2014, p. 301). Em sua ficção, particularmente em Duas iguais, Moscovich explora o tema da homofobia institucionalizada mediante personagens femininas que descobrem a própria sexualidade e a atração por pessoas do mesmo sexo durante esse período autoritário, o qual as obriga a atuarem na clandestinidade.

Clara, a protagonista judia de Duas iguais, também encontra oposição religiosa por meio dos postulados patriarcais da Halachá. A perspectiva tradicional da lei judaica com respeito à homossexualidade fundamenta-se em dois versículos da Torá, a saber, Levítico 18:22 e $20: 13,5$ os quais caracterizam o coito homossexual entre homens como uma "abominação". A Bíblia hebraica não considera a questão da cópula homossexual entre mulheres, devido em parte ao posicionamento patriarcal da Torá, o qual concebe a mulher como objeto, e não sujeito, do ato sexual (Sarah, 1995, p. 96); vários comentários rabínicos, porém, proíbem tanto o casamento entre mulheres quanto o tribadismo, a prática do homossexualismo feminino (Alpert, 2007, p. 660). Portanto, o judaísmo rabínico tradicional afirma o casamento heterossexual ser o estado normativo para todo judeu

\footnotetext{
${ }^{4}$ Distingo entre "ato" e "orientação sexual" e/ou "identidade de gênero" porque a Halachá "trata muito mais frequentemente do que as pessoas fazem e não do que elas são" (Riccetti, 2005, p. 262, tradução nossa).

${ }^{5}$ Levítico 18.22: “Com varão não te deitarás, como se fosse mulher: abominação é”. Levítico 20.13: "Quando também um homem se deitar com outro homem como com mulher, ambos fizeram abominação; certamente morrerão; o seu sangue é sobre eles” (Cafetorah, s.d., s.p.).
} 
(Riccetti, 2005, p. 264). Em Duas iguais, a adolescência de Clara coincide com um período durante o qual o posicionamento tradicional relativamente à homossexualidade prevalece na comunidade judaica, dificultando assim a participação da personagem na vida religiosa.

No entanto, o romance, por ser retrospectivo e narrado em primeira pessoa por uma mulher de meia-idade, abrange várias décadas na vida da protagonista, dimensão que possibilita que ela registre e responda a novas formas de pensamento no judaísmo. No que diz respeito à homossexualidade, Duas iguais corrobora a capacidade da teologia judaica de incorporar novas ideias alinhadas com descobertas científicas e avanços sociais. Há uma grande diversidade de posições vis-à-vis à homossexualidade entre os quatro ramos principais do judaísmo (Ortodoxo, Conservador, Reconstrucionista e Reformista) e dentro deles, porém todos têm modificado suas respectivas posturas desde 1973, ano em que a Associação Americana de Psiquiatria (APA) retirou o homossexualismo da lista de transtornos mentais (no Brasil, o Conselho Federal de Psicologia seguiu o exemplo da APA em 1985, ano que marca o fim da ditadura militar e a redemocratização do país).

Até o momento, o Conselho Rabínico da América (RCA), uma das maiores organizações mundiais de rabinos ortodoxos, ainda proscreve a homossexualidade e as uniões entre pessoas do mesmo sexo, embora não exclua os judeus homossexuais de congregações ortodoxas (RCA, 2011, s.p.). Recentemente, o RCA retirou seu apoio a Jews Offering New Alternatives to Healing (JONAH), uma instituição que oferece um tratamento de reorientação sexual, ou "terapia reparativa", após múltiplas organizações internacionais de prestígio denunciarem a suposta "cura gay" (RCA, 2012, s.p.). A Assembleia Rabínica (RA), a associação internacional de rabinos conservadores que supervisiona o trabalho da Comissão da Lei e Padrões Judaicos (CJLS) para o movimento, permitiu a ordenação de rabinos homossexuais e a celebração de uniões de casais do mesmo sexo em 2006; a mesma associação aprovou normas de procedimento para casamentos e divóricios de pessoas do mesmo sexo em 2012 (Dorff, Nevins e Reisner, 2012, p. 1-20).

Os movimentos Reconstrucionista e Reformista, as correntes mais progressistas do judaísmo, propõem uma revisão da postura tradicional judaica, que caracteriza a heterossexualidade como "normal" e a homossexualidade como aberrante (Riccetti, 2005, p. 292). A denominação Reconstrucionista começou a aceitar alunos homossexuais como 
estudantes rabínicos em 1984, ano em que endossou a ordenação de rabinos gays e lésbicas, e aprovou casamentos religiosos para pessoas do mesmo sexo em 1993 (RRA; JRF, 2008, p. 1). Em 2013, a Associação Rabínica Reconstrucionista (RRA) adotou uma resolução para expressar solidariedade e apoio a pessoas LGBT (RRA, 2013, s.p.). O movimento Reformista, que defende os direitos da comunidade LGBT desde a década de 1960, admitiu sinagogas com programas voltados para a inclusão de pessoas homossexuais em 1973; também autorizou os alunos gays e lésbicas a ingressarem no seminário em 1991 (Dorff, 2005, p. 226). A Conferência Central de Rabinos Americanos (CCAR) e a União do Judaísmo Reformista (URJ), principais organizações do movimento, aprovaram resoluções de apoio ao casamento civil para pessoas LGBT em 1996 e 1997, respectivamente, e a CCAR permitiu aos rabinos reformistas presidirem cerimônias (embora não "casamentos" stricto sensu) para judeus do mesmo sexo em 2000 (RAC, s.d., s.p.).

Considerando a evolução do pensamento judaico no que se refere às questões de orientação sexual e identidade de gênero ao longo dos últimos 40 anos, é visível, de um ponto de vista contemporâneo, a possibilidade de reconciliar a fé judaica com a atração física e emocional por pessoas do mesmo sexo, o que resolve um dos três tipos de transgressão prevalentes na ficção de Moscovich. A autora aborda o tabu do casamento misto de maneira parecida, expondo a angústia de personagens judias envolvidas em relações com góis, a qual se atenua com o decorrer do tempo. Embora a proibição contra o casamento misto derive da Torá (Deuterenômio 7:3), ${ }^{6}$ os quatro ramos principais do judaísmo também veem o casamento misto em relação à demografia. Como maioria dos casais mistos não criam os filhos como judeus, aumentam-se assim as dúvidas sobre a sustentabilidade da tradição judaica (Dorff, 2005, p. 219). Portanto, as diferentes denominações judaicas, sejam conservadoras ou liberais, favorecem o casamento endógamo. A RCA condena expressamente o casamento misto, exclui os cônjuges exógamos de posições de liderança e não permite que os rabinos ortodoxos presidam cerimônias mistas (RCA, 1991, s.p.). Os movimentos Conservador (RA; USCJ, 2014, s.p.), Reconstrucionista (JRC, 2014, s.p.) e Reformista (Rosenthal, 2007, p. 377) não apoiam o casamento misto, mas

${ }^{6}$ Deuterenômio 7:30: "nem te aparentarás com elas; não darás tuas filhas a seus filhos e não tomarás suas filhas para teus filhos" (Cafetorah, s.d., s.p.). 
convidam os cônjuges não judeus a participarem das atividades das respectivas congregações, a fim de proverem aos filhos dos casais a educação religiosa. Nas narrativas retrospectivas de Moscovich, os casais em questão expressam um otimismo cauteloso sobre serem aceitos pela comunidade judaica, apesar de o casamento misto representar até hoje um anátema segundo a perspectiva tradicional.

A terceira transgressão recorrente na ficção de Moscovich, o inconformismo no que se refere à escolha de uma profissão, relaciona-se com a educação, a qual constituía um "imperativo cultural" para as famílias judias que imigraram para o Brasil no início do século XX (Elkin, 1998, p. 117). Moscovich, a qual pertence à terceira geração de judeus asquenazes que chegaram ao país patrocinados pelo filantropo alemão Barão Maurice de Hirsch (1831-1896) e sua Jewish Colonization Association (JCA, também ICA) (Dias, 2012, p. 82), documenta esse valor mediante o arquétipo do pai, figura quase ubíqua nos seus contos e romances. Vários dos textos partem da mesma premissa, provavelmente autobiográfica: o pai sonha em ver a filha formada em medicina ou direito, mas esta tem vocação para escritora e torna-se jornalista. Essa decisão, além de decepcionar o pai, potencialmente põe em risco a filha devido à censura da imprensa no Brasil da ditadura militar.

Já contextualizados os tipos de transgressão frequentemente explorados por Moscovich, veremos como eles se manifestam nos seus contos antes de abordarmos os romances. Três das quatro coletâneas de contos lançadas pela autora apresentam temas que se inserem no âmbito deste estudo, com a exceção de Anotações durante o incêndio (2000).

\section{O reino das cebolas (1996)}

A primeira coleção de Moscovich compreende 15 contos organizados em três seções. A dedicatória do livro - "à memória de meu pai" (Elias Moscovich) - alude não só à reverência que a autora sente pelo pai falecido, mas também à presença contínua que ele exerce na sua ficção. Em "Sheine meidale", conto que trata da relação entre um judeu tradicional e sua filha adolescente, Moscovich salienta o papel autoritário desempenhado pela figura paterna. O título, um termo iídiche que significa "moça bonita", refere-se a um apelido dado à filha pelo pai para expressar carinho, bem como para indicar aprovação quando o comportamento e a aparência dela alinham-se com as normas 
e expectativas patriarcais. Ao longo do conto, a filha, a qual narra em primeira pessoa, registra ou antecipa problemas resultantes do seu inconformismo com respeito ao papel que o judaísmo tradicional lhe assigna. Por exemplo, comenta que o pai apavora-se com o fato de a filha se apaixonar pelo futebol e ignorar por completo as bonecas e os faz-de-conta-de-casinha (Moscovich, 1996, p. 50-51).

Contudo, a maior angústia da personagem-narradora deriva de seu romance secreto com Luiz, um rapaz gói da vizinhança. Fica claro que esse "namoro", o qual se fundamenta na curiosidade de dois adolescentes inexperientes, tem pouco ou nada a ver com o afeto mútuo que caracteriza relações mais sérias e duradouras; a jovem, porém, projeta-se para o futuro, prevendo assim as consequências desastrosas de casar-se com Luiz: ou o pai a mataria (Moscovich, 1996, p. 56) ou "o mundo pararia de girar" (Moscovich, 1996, p. 64-65). No fim de contas, evita-se a catástrofe devido ao fato de a moça terminar o relacionamento com Luiz a favor de Márcio, um rapaz judeu do agrado do pai. Nesse caso, a protagonista não subverte os padrões patriarcais, mas antes se conforma à vontade do pai - a qual corresponde, com efeito, à própria, tendo em vista suas descrições efusivas de Márcio. Ao contrário das protagonistas dos romances, ela consegue um parceiro "apropriado", transformando-se assim em "sheine meidale", a "linda mocinha" do pai (Moscovich, 1996, p. 66).

A última seção da coletânea, intitulada "O outro lado das histórias", consiste em quatro contos sobre relações homoafetivas entre mulheres. Nenhum dos contos apresenta a homoafetividade em relação aos preceitos do judaísmo tradicional, mas, sim, como uma contravenção às normas sociais. Todos desafiam os padrões da heteronormatividade ao proporem que toda paixão, quer seja homo ou heterossexual, é questão do destino e, portanto, natural.

O primeiro conto da seção, "Mi Buenos Aires querido", acontece na capital argentina e descreve um encontro amoroso entre a narradora inominada, uma estudante de microbiologia, e Carmencita, uma cantora de tango. O sexo da narradora é ambíguo devido à total falta de indicações textuais explícitas, sejam gramaticais (i.é artigos, substantivos e adjetivos femininos) ou de conteúdo, porém várias pistas insinuam que ela é mulher. Além de os outros três contos da mesma seção tratarem do homoerotismo feminino, o começo de "Mi Buenos Aires querido" descreve o cruzamento da Avenida Sante Fé com a 9 de Julho em termos de duas noivas beijando-se (Moscovich, 1996, p. 96); a narradora e 
Carmencita reprisam esse beijo no mesmo local no fim da história (Moscovich, 1996, p. 104). A narradora também comenta que as colegas de faculdade não entendem seu interesse pela tangueira (Moscovich, 1996, p. 103); se a narradora fosse homem, as outras alunas provavelmente não estranhariam o "interesse", já que este se enquadraria às suas expectativas heteronormativas. Portanto, a demonstração pública de afeto, bem no meio de uma área de alta visibilidade e grande circulação, não só celebra a paixão das amantes, mas também desafia abertamente os padrões patriarcais da época.

O próximo conto, "A memória das coisas afastadas", introduz temas e situações que Moscovich desenvolverá mais extensivamente em Duas iguais, inclusive a infidelidade marital e a morte iminente e trágica de uma amada. A história apresenta a paixão que irrompe entre duas mulheres brasileiras logo após um encontro casual em Paris. Marilina, mulher casada e mãe de uma filha que está cursando a faculdade, e a amante inominada continuam seu caso em segredo após voltarem ao Brasil, sendo Berta, a amiga de Marilina, a única pessoa que sabe da relação. Esta avisa a amante quando Marilina sofre ferimentos graves após um acidente de carro, situação que leva ao encontro culminante do esposo, a filha e a amante de Marilina no hospital.

Além de desempenhar um papel vital no que se refere ao enredo, Berta funciona como porta-voz de ideias tradicionais, porém moderadas. Por um lado, escuta e ajuda a amiga; por outro lado, pensa que as ações de Marilina constituem uma "parvoíce" (Moscovich, 1996, p. 106) e um "mal pernicioso" (Moscovich, 1996, p. 110). Contudo, a narrativa privilegia a perspectiva de Marilina, a qual insiste ao longo do conto que a paixão é questão de fatalidade. A autora salienta esse argumento na única descrição de sexo elaborada no conto: "Deitou-se ao lado da moça e aceitou e ofereceu, amaram-se, prazer, prazer, e não mais se sabia se era coisa de homem ou de mulher. Era coisa de paixão. Fatalidade, pois" (Moscovich, 1996, p. 108). Segundo o trecho, no qual Moscovich emprega discurso indireto livre para expressar a euforia de Marilina, a paixão não discrimina em razão da orientação sexual; por conseguinte, a repressão do amor entre pessoas do mesmo sexo, e não o amor homossexual em si mesmo, vai contra a natureza.

Os últimos dois contos da seção, "A balada dos gineceus" e "Lírica", descrevem o amor entre uma fotógrafa inominada, que narra em primeira pessoa, e Annika, uma mulher sueca. A primeira narrativa apresenta-se 
como um fluxo de consciência, registrando assim os pensamentos da personagem-narradora enquanto se prepara para uma viagem. $\mathrm{O}$ acesso à mente da fotógrafa revela suas preocupações referentes à mãe descobrir sua relação com Annika; tais preocupações derivam, em grande parte, da sua recusa da função procriativa própria da mulher: "se minha mãe sonhasse que tenho este romance com outra mulher minha mãe vive dizendo que quer um neto mas o amor que eu sinto é estéril duas vaginas não procriam" (Moscovich, 1996, p. 116). Não obstante, afirma a ideia de que a paixão é fatalidade, valendo-se de um trecho do romance Rayuela (1963), do escritor argentino Julio Cortázar: "Como se se pudesse eleger no amor como se não fosse um raio que te parte os ossos e te deixa estaqueado no meio do pátio" (Moscovich, 1996, p. 115, tradução nossa). ${ }^{7}$ "Lírica" continua com a mesma cena, ainda desde a perspectiva da fotógrafa, embora a narrativa passe de fluxo de consciência para monólogo interior. O miniconto, o qual consiste principalmente na descrição erótica do corpo de Annika enquanto dorme, inverte as metáforas do misticismo literário para expressar o êxtase da personagem-narradora, caracterizando o prazer sensual - o beijo da amante - em termos espirituais: "E, agora, o beijo de Annika, a visão mais clara da divindade, a epifania mais evidente, o momento de graça permitido" (Moscovich, 1996, p. 119). Essa técnica figurará proeminentemente em Duas iguais.

\section{Arquitetura do arco-íris (2004)}

Talvez o título da coletânea refira-se à bandeira arco-íris, símbolo internacional do movimento LGBT, embora apenas um dos dez contos que integram a coleção trate de uma relação homoafetiva. "Cartografia" focaliza a atração da personagem-narradora inominada, uma mestranda em estudos literários, por sua colega de faculdade e companheira de

\footnotetext{
${ }^{7}$ A citação não é exata: "Como si se pudiese elegir en el amor, como si no fuera un rayo que te parte los huesos y te deja estaqueado en la mitad del patio" (Cortázar, 1989[1963], p. 593, grifo nosso). Moscovich tende a colocar "easter eggs" (referências incorporadas) provenientes de textos de outros autores latino-americanos na própria ficção. Em "Mi Buenos Aires querido" encontramos "Ninguém ignora que o Sul principia do outro lado da Rivadavia" (Moscovich, 1996, p. 98), frase de "El sur" de Jorge Luis Borges. De modo semelhante, o cego mastigante, originário de "Amor" de Clarice Lispector, aparece em "Fantasia-Improviso" (Moscovich, 2004a, p. 56). Além dessas piscadas de olho para o leitor, há histórias de Moscovich que sustentam diálogos intertextuais com a obra de outros autores; consideremos as semelhanças entre "O telhado e o violinista" e "A galinha" de Lispector; "Os laços e os nós, os brancos e os azuis" (Moscovich, 2004) e "Os laços de família" de Lispector; e "Aquilo que não principia nem acaba" (Moscovich, 2001) e "El libro de arena" de Borges.
} 
quarto, Beatriz, personagem cuja correspondência com a xará dantesca evidencia-se na sua "vocação arrasadora para despertar paixões e não correspondê-las" (Moscovich, 2004a, p. 47). Como de costume na ficção de Moscovich, a história acontece logo após a morte do pai da narradora; esta, aos 28 anos, ainda está à espera da "grande tragédia sentimental" que vai lhe tocar na vida (Moscovich, 2004a, p. 47). Sente uma afinidade imediata e profunda por Beatriz, a qual descreve como "uma companhia tão antiga que parecia ter estado comigo na remota manhã de minha infância" (Moscovich, 2004a, p. 46). Apesar de caracterizar a colega como sua alma gêmea, a narradora não tem conhecimento da própria sexualidade no momento; o leitor atento acompanha seu lento despertar, ciente da atração devido a passagens levemente eróticas, como a seguinte:

Depois do banho, que invadiu o apartamento numa nuvem cheirosa, apareceu de pijama e pantufas em meu quarto: os cabelos ainda úmidos cintilavam numa feroz chama ruiva. $\mathrm{Eu}$, que me enredava nos cabos do computador, me impressionei com a primeira aproximação - uma intimidade assim repentina. $\mathrm{O}$ decote em formato de $\mathrm{V}$ marginava o colo alvo, uma pele claríssima que ia se alongar no pescoço e no rosto de contornos redondos e delicados (Moscovich, 2004a, p. 45).

Finalmente, a narradora compreende por que a proximidade física com Beatriz inquieta-a, mas mantém silêncio. A amiga, inconsciente dos sentimentos da personagem-narradora, muda-se, deixando-a só, tal como uma viúva (Moscovich, 2004a, p. 53).

O conto "Bonita como a lua", novamente dedicado à memória de Elias Moscovich, retoma o tema da relação pai-filha já explorado em "Sheine meidale". O conto apresenta os esforços da personagem-narradora para agradar ao pai, o qual é venerado por ela. Caracteriza-se como o arquétipo do pai judeu; o "patriarca" despreza o sonho da filha de ser escritora e atriz (Moscovich, 2004a, p. 155) e insiste que estude para ser médica ou advogada (Moscovich, 2004a, p. 157). A filha obediente tenta cursar medicina e direito, sem sucesso; conclui, portanto, que seu destino é ser escritora: "Então é isso: escrevo porque é o que me foi dado fazer no mundo, porque acho que nasci com isso" (Moscovich, 2004a, p. 170, grifo da autora). Aqui argumenta que a vocação, como a paixão, é pura fatalidade, afirmando assim sua escolha de carreira.

Além de tornar-se escritora, a filha contravém as normas do pai ao casar-se com um gói. O falecimento prévio aos acontecimentos poupa o 
pai do desapontamento, porém a personagem-narradora acredita que ele teria aceitado sua decisão ao final: "Isso [o casamento] certamente teria feito a amargura do pai. Mas sei que poderíamos ter negociado para chegar a um bom termo" (Moscovich, 2004a, p. 170). A fé na magnanimidade do pai, atributo concedido a título póstumo, será a chave para a autora reconciliar a lei judaica com o homossexualismo em Duas iguais, e com o casamento misto em Por que sou gorda, mamãe?

\section{Essa coisa brilhante que é a chuva (2012)}

O conto "A balada de Avigdor" é uma novidade na ficção de Moscovich, tanto pela temática quanto pela conclusão. Primeiro, é a única obra da autora a abordar o tema do homossexualismo em um contexto masculino. Descreve o desespero de Samuel Goldamovich, um pai judeu, quando o único filho, Avigdor, apaixona-se pelo balé, preferência que Samuel automaticamente associa à homossexualidade. A personagem do pai é uma caricatura do homófobo estereotípico; acha que o filho, aos oito anos, precisa de "estímulos mais eficientes à virilidade" (Moscovich, 2012, p. 46), preocupa-se com o guri virar "um frisher, um maricas, um mãotorcida" (Moscovich, 2012, p. 50) e ameaça deserdá-lo se não abandonar as aulas de dança (Moscovich, 2012, p. 56). Contudo, Samuel muda de ideia ao saber que Avigdor está namorando a vizinha, Débora, sua amiga de infância. Finalmente, Avigdor torna-se um bailarino mundialmente conhecido, casa-se com Débora e tem seis filhos, "todos estranhamente normais" segundo o avô (Moscovich, 2012, p. 57). No que se refere ao desfecho, este difere dos de outras histórias de Moscovich, nas quais os conflitos resolvem-se mediante compromissos. Nesse caso, o final feliz depende de a personagem "transgressiva" alinhar-se completamente aos padrões patriarcais, reforçando assim o statu quo heteronormativo e pondo termo a ideais progressistas.

\section{Duas iguais (1998)}

No seu estudo da ficção de Cíntia Moscovich, Nancy Rozenchan refere-se a Moacyr Scliar e sua categorização da chamada "literatura étnica" em três momentos ou "gerações" (no sentido genérico do termo). Segundo Rozenchan, Moscovich pertence à terceira geração de escritores, para os quais os conflitos identitários resultantes de processos 
assimilativos já não causam grandes estragos, seja em suas vidas ou nas das personagens. Para sustentar seu argumento, Rozenchan destaca o tratamento da homossexualidade e do casamento misto na obra de Moscovich. Com respeito ao primeiro tema, observa que, em Duas iguais, a autora focaliza a relação homossexual entre a personagem-narradora, Clara, e sua amiga, Ana, relegando assim a questão do judaísmo para segundo plano (Rozenchan, 2006, p. 79-80). No que se refere ao segundo tema, leva em consideração a apresentação da exogamia em textos anteriores, comentando "uma perspectiva inadmissível para a geração dos imigrantes - o casamento com um não judeu - recebe, na obra de Moscovich, um tom suave através de vários dispositivos literários, alguns dos quais merecem a nossa atenção" (Rozenchan, 2006, p. 80, tradução nossa). Com isto, Rozenchan propõe que as mais duras polêmicas do passado reduzem-se na ficção de autores judeus contemporâneos, tornando-se meros inconvenientes ou vestígios da época dos pais e/ou avós.

A leitura de Rozenchan não confere importância ao trauma sofrido pelas personagens de Moscovich quando transgridem as normas do judaísmo. Nos romances da autora, esse trauma manifesta-se nas relações pai-filha e envolve personagens-narradoras cuja angústia ao contravirem a autoridade paterna torna-se o foco de uma análise sustentada. Assim acontece em Duas iguais, obra que sintetiza os três correlativos principais do patriarcado na obra de Moscovich (a ditadura militar, a Halachá e a figura do pai), bem como as três "transgressões" (as relações mistas, as relações homoafetivas e o inconformismo no que se refere às escolhas de carreira).

Devido a fatores políticos e religiosos, o romance entre Clara e Ana torna-se triplamente transgressivo. Embora a narrativa, escrita retrospectivamente, abranja um período de vinte a trinta anos, o início da relação amorosa acontece durante a adolescência das amigas, em plena ditadura militar. $\mathrm{O}$ texto contém várias referências à corrupção e à violência do regime, inclusive à morte suspeita de um jornalista judeu (presumivelmente Vladimir Herzog) na prisão, a tortura de prisioneiros políticos e o sequestro do professor de Física da escola das personagens por um grupo de homens vestidos com ternos escuros (Moscovich, 2004b, p. 26-28). Para o pai de Clara, o ambiente político ameaçador serve de pretexto para desaprovar a amizade entre a filha e Ana, devido a boatos sem fundamento de que os pais desta estariam ligados a grupos políticos 
clandestinos (Moscovich, 2004b, p. 25). Contudo, o verdadeiro risco para as personagens - a perseguição de pessoas homossexuais durante a ditadura - evidencia-se na narrativa com a caracterização da sua relação como um ato subversivo. Segundo a personagem-narradora, sua paixão equivale a "uma situação clandestina" (Moscovich, 2004b, p. 42); ela e Ana são descobertas e "delatadas" por uma colega, Beatriz Levi (Moscovich, 2004b, p. 46); e vivem sob o medo constante de serem vigiadas: "E agora ela [Ana] não podia sequer me abraçar sem antes investigar se alguém estava nos espionando" (Moscovich, 2004b, p. 47). O desespero de Clara chega a tal ponto que comenta, "Mil vezes pensei que teria preferido que os homens de ternos escuros tivessem vindo para me dar sumiço" (Moscovich, 2004b, p. 47). Portanto, o emprego de referências e vocábulos específicos ao ambiente político e social da época contribuem para a descrição do amor "ilícito" entre Clara e Ana em termos de um crime contra o Estado.

Ao mesmo tempo, sua paixão viola as normas do judaísmo ortodoxo, em grande parte por ambas serem mulheres, mas também por Ana ser católica. Como anteriormente visto no conto "Lírica", as cenas homoeróticas, valendo-se de imagens cristãs, invertem as metáforas do misticismo literário para retratarem o amor carnal em termos do fervor religioso. O desejo de Clara assume proporções blasfemas quando ela atribui qualidades divinas a Ana: "Te venerei, como não se deve venerar ser humano algum; mas já eras santa, eras a única figura em que eu acreditava, a deificação na minha pupila, o milagre do vinho em sangue, a apoteose da Humanidade - ascendias aos céus na tua blusa azul" (Moscovich, 2004b, p. 151). Além de idólatra, o ato de fazer amor com Ana representa uma forma de apostasia para Clara: "escutei meu nome dito por ti como quem escuta a própria Palavra. Coloquei-me de joelhos ao primeiro batismo de minha vida, à consagração que me dava a santidade de tua voz; ajoelhei-me ao pé de ti, deixei-me persignar testa boca peito por tuas estranhas cruzes" (Moscovich, 2004b, p. 220). Assim, a personagem-narradora encontra-se perante uma escolha impossível: separar-se de Ana ou abandonar a fé.

No início, Clara escolhe a primeira opção. Ela e Ana decidem mutuamente afastar-se uma da outra durante um futuro previsível; enquanto Ana vai estudar na França, Clara casa-se com Vítor, um arquiteto judeu. É óbvio que o desejo de agradar ao pai, embora já falecido, motiva as ações da personagem-narradora: consegue um 
marido judeu que trabalha na construtora da família, exatamente como o pai havia esperado (Moscovich, 2004b, p. 107). Segundo confirma o Dr. Rosenblatt, velho amigo da família e figura autorizada nos romances de Moscovich, o pai "teria se orgulhado" da filha no dia do casamento (Moscovich, 2004b, p. 139); esta tenta estabelecer um lar judaico com Vítor, porém admite não amá-lo (Moscovich, 2004b, p. 164-165).

A descrição da natureza da relação entre Vítor e Clara contribui para uma discussão sobre a orientação sexual desta, embora a narrativa mantenha certa ambiguidade a respeito. Clara admira o esposo, mas confia que não lhe desperta paixão (Moscovich, 2004b, p. 118); no que se refere ao aspecto físico, salienta a "beleza quase feminil" (Moscovich, 2004 b, p. 128), porém não se sente sexualmente atraída por Vítor. Ao contrário, a química entre Clara e Ana é palpável; isto, no entanto, não significa que Clara seja lésbica. Ela mesma questiona a designação: "Lésbica. Me olhava no espelho e não enxergava a lésbica ali. Eu queria Aninha, eu não queria nenhuma outra mulher, me desesperava" (Moscovich, 2004b, p. 47). O fato de Clara ignorar por completo que Natália, sua colega de trabalho, está apaixonada por ela parece corroborar seu interesse particular por Ana (Moscovich, 2004b, p. 168). Considerando-se os detalhes, é possível que Clara seja demissexual, ou seja, uma pessoa que somente sente atração sexual por alguém após formar um forte laço emocional com ele/ela, independentemente do gênero (Galupo et al., 2014, p. 446-447).

Seja como for, os sentimentos persistentes da personagem-narradora, por serem transgressivos perante a lei judaica, produzem nela uma profunda crise espiritual. Como resultado, sofre de dores de cabeça que, segundo o diagnóstico do Dr. Rosenblatt, são psicossomáticas. Clara concorda, afirmando que "os males da alma eram a causa de meu padecimento" (Moscovich, 2004b, p. 139). Para Dias, cuja análise dos romances de Moscovich focaliza a apresentação do corpo feminino, as consequências deletérias de resistir às normas patriarcais manifestam-se fisicamente como doenças e deformações. Dessa maneira, explica não só as enxaquecas de Clara, mas também o tumor cerebral que leva Ana à morte: "As cabeças de Aninha e Clara estão doentes, pois, de acordo com a lei mosaica, seus pensamentos são deformados e enfermiços" (Dias, 2012, p. 100). A leitura de Dias admite pelo menos duas interpretações do sofrimento. Por um lado, pode ser punitivo, ou seja, um castigo aplicado a quem pretenda contestar as regras do 
patriarcado. Por outro lado, pode refletir a dor ontológica implícita em romper com a tradição e em questionar a própria formação identitária com respeito ao papel que lhe é atribuído.

A dinâmica pai-filha na ficção de Moscovich confirma a segunda dessas interpretações. Na opinião de Schwantes, Duas iguais constitui um Bildungsroman em que Clara tenta reconciliar sua "opção sexual não convencional" com a fé judaica e a identidade feminina (Schwantes, 2007, p. 57); esse processo exige que ela revisite a dolorosa história da sua adolescência, a qual coincide com o afastamento da fé, à luz de correntes de pensamento judaicas mais recentes e liberais. $\mathrm{O}$ falecimento prematuro do pai, o porta-estandarte do judaísmo tradicional, permite que Clara lhe atribua ideias progressistas a título póstumo no que se refere à orientação sexual. A adaptabilidade do pai já havia sido evidenciada com respeito à profissão da filha: inicialmente proíbe que siga a carreira de jornalista (Moscovich, 2004b, p. 28-29); depois, abranda e resigna-se à decisão (Moscovich, 2004b, p. 107). As palavras do sábio Dr. Rosenblatt também alentam a personagem-narradora; Dr. Rosenblatt, ciente do amor duradouro entre Ana e Clara, comenta: "Seu pai, se fosse vivo, talvez soubesse entender" (Moscovich, 2004b, p. 236). Embora as evidências da flexibilidade paterna sejam fracas e, por razões óbvias, especulativas, possibilitam que Clara afirme a naturalidade do seu amor por Ana e, ao mesmo tempo, honre a memória do pai, de quem sente enormes saudades.

\section{Por que sou gorda, mamãe? (2006)}

Na superfície, o romance focaliza a personagem-narradora inominada, uma mulher judia de meia-idade, e sua vida de luta contra a obesidade. Como o título sugere, a mãe apresenta-se como a destinatária da prosa; a interlocutora, porém, se mantém em silêncio ao longo da narrativa. De fato, o pai, que havia falecido aproximadamente trinta anos antes da escrita, parece estar mais presente no texto do que sua viúva, já que os ditames dele continuam a pesar sobre a filha durante décadas. Nesse romance, assim como em outras obras de Moscovich, a narradora escreve na esperança de resolver conflitos de longa data com o pai.

De acordo com Góis, Moscovich emprega a obesidade como símbolo de alteridade: "ser gordo na obra significa estar desajustado e sentir-se renegado, deslocado" (Góis, 2009, p. 69). A condição física da 
protagonista também se relaciona com transtornos de origem espiritual; ela afirma, "Minha alma decerto se mostra no corpo" (Moscovich, 2006, p. 17). Atribui o aumento de peso à imprevidência de carácter moral, observando que "meu corpo e minha consciência se divorciaram" (Moscovich, 2006, p. 14); como resultado, é atingida por "remoeduras de culpa" (Moscovich, 2006, p. 157). Novamente, compete ao pai ensinar e defender os valores tradicionais da família. Segue-se, portanto, que a angústia e a despertença da personagem-narradora devem-se, em grande parte, à contravenção desse valores. Nesse sentido, o romance valida a análise de Dias, a qual, como anteriormente mencionado, associa a desfiguração física à resistência ao patriarcardo.

Algumas das "transgressões" da protagonista são as mesmas que Moscovich explora em outros textos, como o casamento com um gói, Ricardo, e a decisão de seguir a carreira de escritora em vez de médica ou advogada. A transgressão mais óbvia, se tomada por seu valor aparente, seria o sobrepeso, visto que o pai impõe uma dieta rigorosa em casa - a narradora explica: "Tudo o que não fosse do jeito e na hora em que deveria era corrupção, vício ou engordava" (Moscovich, 2006, p. 93). No entanto, o fato de a "proibição de comer" coincidir com a puberdade da protagonista, detalhe salientado por ela (Moscovich, 2006, p. 207), prestase a interpretações além da literal. Por exemplo, a reprovação do pai contra os "excessos" possui uma aplicação geral: "Havia uma medida nas coisas e devíamos aprendê-la. As coisas todas têm um método. Até a gordura" (Moscovich, 2006, p. 219). Dado o incipiente amadurecimento físico da filha, não seria demais extrapolar desse conselho paterno uma dica relativa à moderação do apetite sexual.

A personagem-narradora, tal como sua homóloga em Duas iguais, recorre ao Dr. Rosenblat (aqui escrito com um " $\mathrm{t}$ " em vez de dois) na tentativa de reconciliar sua situação com as expectativas do pai. Ocorrelhe perguntar ao íntimo amigo do pai o que este, na sua opinião, pensaria sobre ter uma filha escritora; o doutor responde de forma sucinta, "Ele toleraria" (Moscovich, 2006, p. 236). Embora a protagonista confesse não saber o que o pai pensaria do esposo gói (Moscovich, 2006, p. 236), também indica que para ela importa muito pouco, ao comentar, "Acho que os mortos podem ser moldados de acordo com as necessidades dos vivos" (Moscovich, 2006, p. 185). No fim de contas, a suposta adaptabilidade do pai talvez tenha mais a ver com a licença criativa do que com razões válidas. 
Pode-se concluir, portanto, que as caracterizações dos pais na ficção de Moscovich refletem a mitigação gradativa da autoridade de instituições patriarcais, a saber, o Estado e o conselho rabínico ortodoxo, desde a época da ditadura militar no Brasil. A autora expressa uma mistura de sentimentos com respeito às mudanças que tem testemunhado e documentado em suas obras retrospectivas. Por um lado, exprime seu otimismo cauteloso relativo à capacidade do pensamento judaico para evoluir com o tempo e à luz de novos descobrimentos e entendimentos científicos. Nesse sentido, afirma os avanços do movimento LGBT não só na sociedade em geral, mas também nos ramos progressistas do judaísmo. Esse progressismo traduz-se narrativamente no dinamismo do arquétipo do pai, cuja postura tradicional abranda-se ao longo dos textos.

Por outro lado, as caracterizações dos pais são, em grande parte, especulativas, já que as perspectivas e atitudes cada vez mais liberais são-lhes atribuídas, merecida ou imerecidamente, a título póstumo, fator que sugere certa reticência por parte da autora. Além disso, essas perspectivas e atitudes não passam de "tolerância" para com os desejos e as decisões das filhas; no entanto, a verdadeira reconciliação requereria não só uma tolerância unilateral e paternalista, mas também a compreensão, a afirmação e o respeito mútuo. Portanto, vale dizer que a ficção de Moscovich, embora reconheça o progresso em direção a um maior igualitarismo construído até a presente data, também revela que há ainda muito a se fazer.

\section{Referências}

ALPERT, Rebecca (2007). Lesbianism. In: BERENBAUM, Michael; SKOLNIK, Fred (Org.). Encyclopaedia judaica. 2. ed. v. 12. Detroit: Macmillan Reference. p. 660-661.

APA - AMERICAN PSYCHOLOGICAL ASSOCIATION (2011). Definition of terms: sex, gender, gender identity, sexual orientation. On-line. Disponível em: <http://goo.gl/cic6la>. Acesso em: 28 mar. 2015.

CAFETORAH (s.d.). A Bíblia em hebraico e português versículo por versículo. Cafetorah Notícias de Israel. On-line. Disponível em: <http://goo.gl/Q4sDXy>. Acesso em: 30 mar. 2015.

CORTÁZAR, Julio (1989[1963]). Rayuela. 5. ed.: Madrid: Cátedra. 
GÓIS, Edma Cristina de (2009). A procura de si: a representação do corpo gordo em Cíntia Moscovich. Estudos de Literatura Brasileira Contemporânea, n. 33, p. 59-70.

DIAS, Selene de Souza (2012). As representações do corpo feminino na literatura e nas artes visuais judaicas da América Latina. Tese (Doutorado) - Programa de PósGraduação em Espanhol, University of Arizona.

DORFF, Elliot N. (2005). The Jewish family in America: contemporary challenges and traditional resources. In: BROYDE, Michael J. (Org.). Marriage, sex, and family in Judaism. Lanham: Rowman \& Littlefield Publishers. p. 214-243.

DORFF, Elliot; NEVINS, Daniel; REISNER, Avram (2012). Rituals and documents of marriage and divorce for same-sex couples. On-line. Disponível em: <http:/ /goo.gl/qS14wN>. Acesso em: 16 mar. 2014.

ELKIN, Judith Laikin (1998). The Jews of Latin America. New York: Holmes \& Meier.

FOSTER, David (2009). Ensayos sobre culturas homoeróticas latinoamericanas. Ciudad Juárez: Universidad Autónoma de Ciudad Juárez.

FOSTER, David (1991). Gay and lesbian themes in Latin American writing. Austin: University of Texas Press.

GALUPO, M. Paz et al. (2014). Conceptualization of sexual orientation identity among sexual minorities: patterns across sexual and gender identity. Journal of Bisexuality, v. 14, n. 3-4, p. 433-456.

GREEN, James N.; CÉSPEDES, Carlos Manuel de; QUINALHA, Renan (2014). Ditadura e homossexualidades. In: PINHEIRO, Paulo Sérgio (Org.). Relatório da Comissão Nacional da Verdade. v. 2. Brasília: CNV. p. 300-311.

JRC - JEWISH RECONSTRUCTIONIST COMMUNITIES (2014). FAQs on Reconstructionist approaches to Jewish ideas and practices. On-line. Disponível em: <http://goo.gl/Y3Hvic>. Acesso em: 16 mar. 2015.

MOSCOVICH, Cíntia (2001). Anotações durante o incêndio. 2. ed. Porto Alegre: L\&PM.

MOSCOVICH, Cíntia (2004). Arquitetura do arco-íris. Rio de Janeiro: Record.

MOSCOVICH, Cíntia (2004b [1998]). Duas iguais. Rio de Janeiro: Record.

MOSCOVICH, Cíntia (2012). Essa coisa brilhante que é a chuva. Rio de Janeiro: Record.

MOSCOVICH, Cíntia (1996). O reino das cebolas: contos e narrativas. Porto Alegre: Prefeitura Municipal de Porto Alegre/Fumproarte/Mercado Aberto.

MOSCOVICH, Cíntia (2006). Por que sou gorda, mamãe? Rio de Janeiro: Record. 
RA - RABBINICAL ASSEMBLY; USCJ - UNITED SYNAGOGUE OF CONSERVATIVE JUDAISM (2014). RA and USCJ statement on keruv and intermarriage. On-line. Disponível em: <http://goo.gl/HVgDNj>. Acesso em: 16 mar. 2015.

RCA - RABBINICAL COUNCIL OF AMERICA (1991). Mixed marriage. Online. Disponível em: <http://www.rabbis.org/news/article.cfm?id=101032>. Acesso em: 16 mar. 2015.

RCA - RABBINICAL COUNCIL OF AMERICA (2012). Rabbinical Council of America's statement regarding JONAH (Jews Offering New Alternatives to Homosexuality). On-line. Disponível em: <http:/ / www.rabbis.org/news/article.cfm?id=105723>. Acesso em: 15 mar. 2015.

RCA - RABBINICAL COUNCIL OF AMERICA (2011). RCA reaffirms policies regarding same sex attraction and marriage, while clarifying its position on reparative therapy. On-line. Disponível em: <http:/ / www.rabbis.org/news/article.cfm?id=105665>. Acesso em: 15 mar. 2015.

RRA - RECONSTRUCTIONIST RABBINICAL ASSOCIATION (2013). Resolution on gender identity. On-line. Disponível em: <http://goo.gl/6nUP6D>. Acesso em: 16 mar. 2015.

RRA - RECONSTRUCTIONIST RABBINICAL ASSOCIATION; JRF - JEWISH RECONSTRUCTIONIST FEDERATION (2008). Judaism's Reconstructionist movement condemns bans on same-sex marriage: denunciation reflects longstanding leadership of push to liberalize Jewish approaches to homosexuality. On-line. Disponível em: <http://goo.gl/2pW2lD>. Acesso em: 16 mar. 2015.

RAC - RELIGIOUS ACTION CENTER OF REFORM JUDAISM (s.d.). LGBT rights and position of the Reform movement. On-line Disponível em: <http:/ / www.rac.org/lgbt-rights-and-position-reform-movement>. Acesso em: 16 mar. 2015.

RICCETTI, Angela J. (2005). A break in the path: lesbian relationships and Jewish law. In: BROYDE, Michael J. (Org.). Marriage, sex, and family in Judaism. LanhaM: Rowman \& Littlefield Publishers, Inc. p. 262-294.

ROSENCHAN, Nancy (2006). Cíntia Moscovich's Brazilian view on Jewish literary themes. Journal for the Study of Religion, Grahamstown, v. 19, n. 2, p. 77-86.

ROSENTHAL, Erich, et al. (2007). Mixed marriage, intermarriage. In: BERENBAUM, Michael; SKOLNIK, Fred (Org.). Encyclopaedia Judaica. 2. ed. v. 14. Detroit: Macmillan Reference. p. 373-385. 
SARAH, Elizabeth (1995). Judaism and lesbianism: a tale of life on the margins of the text. In: MAGONET, Jonathan (Org.). Jewish explorations of sexuality. Providence: Berghahn Books. p. 95-101.

SCHWANTES, Cíntia (2007). Narrativas de formação contemporânea: uma questão de gênero. Estudos de Literatura Brasileira Contemporânea, n. 30, p. 53-62.

Recebido em abril de 2015.

Aprovado em setembro de 2015.

\section{resumo/abstract/resumen}

\section{A contravenção do patriarcado na ficção de Cíntia Moscovich}

James Hussar

Este estudo focaliza a dinâmica pai-filha como um meio pelo qual a autora gaúcha Cíntia Moscovich (1958- ) contesta padrões patriarcais na sua ficção. O arquétipo do pai serve como ponto da partida para Moscovich apresentar as normas patriarcais da lei judaica e do Estado brasileiro da época da ditadura militar. No entanto, as filhas, sempre personagens-narradoras, questionam e transgridem essas normas. Suas transgressões incluem relações amorosas vedadas (entre pessoas do mesmo sexo e/ou entre judeus e góis) e inconformismo no que se refere à escolha de carreira. Ao longo das narrativas, as protagonistas tentam reconciliar as diferentes facetas identitárias - a brasileira, a judaica e a sexual que compõem seu sentido de si. A presente análise literária considera os principais pontos da teoria queer e a trajetória do pensamento progressista nos quatro maiores ramos do judaísmo durante os últimos 40 anos.

Palavras-chave: patriarcado, lei judaica, teoria queer, Cíntia Moscovich.

\section{The contravention of patriarchy in the fiction of Cíntia Moscovich}

\section{James Hussar}

This study focuses on father-daughter relationships as a vehicle through which Rio Grandian author Cíntia Moscovich (1958- ) challenges patriarchal standards in her fiction. The father archetype serves as a starting point for Moscovich to present the patriarchal norms of Jewish law as well as of the Brazilian government under the military dictatorship. The fictional daughters, who double as narrators, question and violate these norms. Their transgressions include prohibited amorous relationships (between same-sex couples and/or between Jews and goys) and nonconformity with regard to career choices. Throughout the narratives, the protagonists attempt to reconcile the contrasting 
aspects of their identities - Brazilianness, Jewishness, and sexual orientation that comprise their sense of self. The literary analysis herein considers the fundamental concepts of queer theory as well as the trajectory of progressive thought in the four main branches of Judaism over the last 40 years.

Keywords: patriarchy, Jewish law, queer theory, Cíntia Moscovich.

\section{La contravención del patriarcado en la ficción de Cíntia Moscovich}

James Hussar

Este estudio se centra en la dinámica padre-hija como un elemento a través del cual la autora Cíntia Moscovich (Rio Grande do Sul, 1958- ) desafía patrones patriarcales en su ficción. El arquetipo del padre sirve como punto de partida desde el cual Moscovich presenta las normas patriarcales de la ley judaica y del Estado brasileño de la época de la dictadura militar. Mientras tanto, las hijas, siempre personajes-narradoras, cuestionan y violan esas normas. Sus transgresiones incluyen relaciones amorosas prohibidas (entre personas del mismo sexo y/o entre judíos y goyim) e inconformidad en cuanto a la selección de una profesión. A lo largo de las narrativas, cada protagonista trata de reconciliar las diferentes facetas de su identidad - la brasileña, la judía y la sexual - que componen el sentido de sí mismas. El presente análisis literario considera tanto los conceptos fundamentales de la teoría queer como la trayectoria del pensamiento progresista en los cuatro ramos principales del judaísmo durante los últimos 40 años.

Palabras clave: patriarcado, ley judaica, teoría queer, Cíntia Moscovich. 